\title{
Brain Abscess Caused by Paradoxical Embolization Associated with Ebstein's Anomaly in Child
}

\author{
Amar Taksande*, Rewat Meshram, Purnima Yadav, Sonal Gore and Amol Lohakare \\ Department of Pediatrics, Jawaharlal Nehru Medical College, India
}

Submission: July 04, 2017; Published: May 25, 2018

*Corresponding author: Amar Taksande, Department of Pediatrics, Jawaharlal Nehru Medical College, Sawangi Meghe, Wardha, Maharashtra 4420004, India, Email: amar.taksande@gmail.com

\begin{abstract}
A 12 year old female child presented with brain abscess. Previous cardiac history was not noticeable. To find out the cause of embolism, echocardiography was done and revealed Ebstein's anomaly (EA) with apical displacement of septal leaflet of the tricuspid valve and ostium secundum type of atrial septal defect (ASD). The combination of high right atrial pressure caused by EA and ASD with possibility of transient right to left shunt predispose for embolization. The most likely reason for development of a brain abscess in our case is septic embolization from an infectious focus outside the heart.
\end{abstract}

Keywords: Ebstein's anomaly; Paradoxical embolisms; Brain abscess

\section{Introduction}

Brain abscess is an intracranial suppurative infection, usually with underlying infection or predisposing factors. Commonly seen in neonates and children between 4-8 years age. It is mainly caused by extension from sinusitis, orbital cellulitis, chronic suppurative otitis media, mastoiditis, congenital heart disease, soft tissue infection of face and scalp, dental infections complicated pneumonia immunodeficiency states, infection of ventriculoperitoneal shunts and penetrating injuries. Mortality is high, up to $60 \%$, if not diagnosed early and treated immediately. Ebstein anomaly is a rare congenital malformation of the heart which is characterized by apical displacement of the septal and posteriortricuspid valve leaflets, leading to right ventricular atrialization. It represents about $0.5 \%$ of congenital heart defects and only $5 \%$ of cases survive beyond the age of $50[1,2]$. Here we report a case of brain abscess which was caused by paradoxical embolism in EA child.

\section{Case Report}

A 12 year female child was referred to our hospital with complaints of headache since 2 months and 2-3 episodes of vomiting since 1 day. Headache was generalized, throbbing in nature, progressively increasing in the last 7 days. Each episode lasted for approx 3-4 hour. Relieved on medication, not associated with any aggravating factors. Headache was associated with vomiting and one episode of convulsion. Vomiting was non projectile in nature, consisting of food particles. No hematemesis and blood in vomitus. Mother gives history of one episode of convulsion with clenching of teeth, frothing from mouth and deviation of angle of mouth to left side, lasting for 1-2 minutes with no postictal drowsiness. There was no history of fever, diplopia, slurring speech, sinusitis, ear discharge or head injury or any other neurological deficit. On 7th day of illness CT scan brain with contrast done from outside which was suggestive of brain abscess (Figure 1).

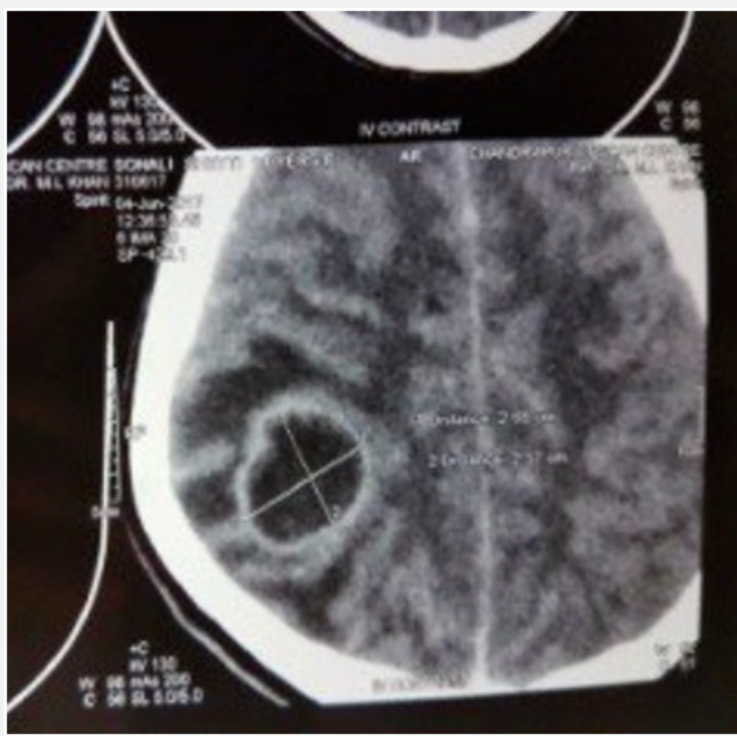

Figure 1: CT scan of the brain with contrast shows brain abscess. 


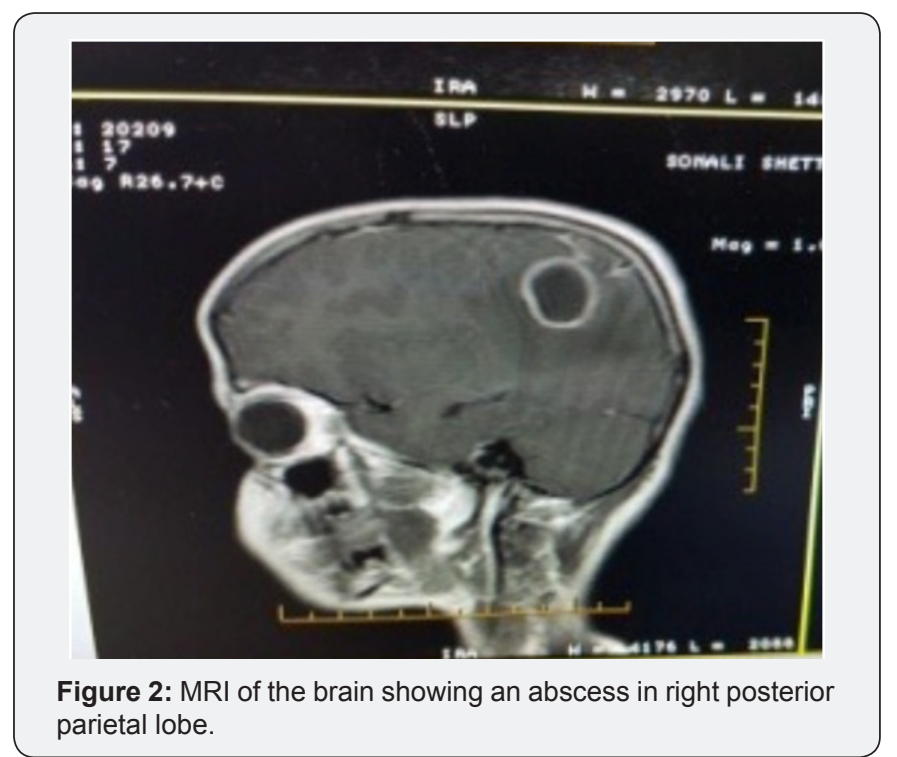

On admission patient was afebrile, oxygen saturation 98\%, blood pressure $100 / 64 \mathrm{~mm} \mathrm{Hg}$, heart rate $98 \mathrm{bpm}$ and and respiratory rate was $20 / \mathrm{min}$. A systolic murmur, grade $2 / 6$ best heard at tricuspid area. Glasgow Coma Scale (GCS) was 15/15. On CNS examination, no neurological deficit. Babinski sign was positive. Other Systemic examination was within normal limits.
Routine blood investigations and CSF examination were normal and blood culture was sterile. No papilloedema on fundus examination. A MRI brain was done on 12th day of illness which revealed features suggestive of cerebral abscess in right posterior parietal lobe. Measuring approx $3.4 \times 2.8 \times 2.7 \mathrm{~cm}$ (Figure 2). Child was put on Inj. Ceftriaxone, Inj. Vancomycin and Inj. Metronidazole [3-5].

The chest X-ray documented cardiomegaly due to enlargement of the right cardiac chambers. ECG shows right axis deviation with right atrial enlargement and wide QRS complex. Echocardiography was done to rule out any underlying congenital cyanotic heart disease, which was suggestive of Ebstein's anomaly with large size Ostium Secundum type of Atrial Septal Defect with mild Tricuspid Regurgitation (Figure 3). Repeat CT brain with contrast was done on 18th day of illness to see the size of abscess which revealed no improvement despite of administration of higher antibiotics for over 7 days. Then patient was taken for surgery by neurosurgeon and drained the abscess. A right parietal craniotomy, excision and evacuation of abscess were done under general anaesthesia. Abscess with thick capsule was seen and thick yellowish pus was drained and sent for culture. The repeat CT scan after operation, showed minimal edema. After receiving total 4 week of antibiotics, patient was discharged with no neurological problem.

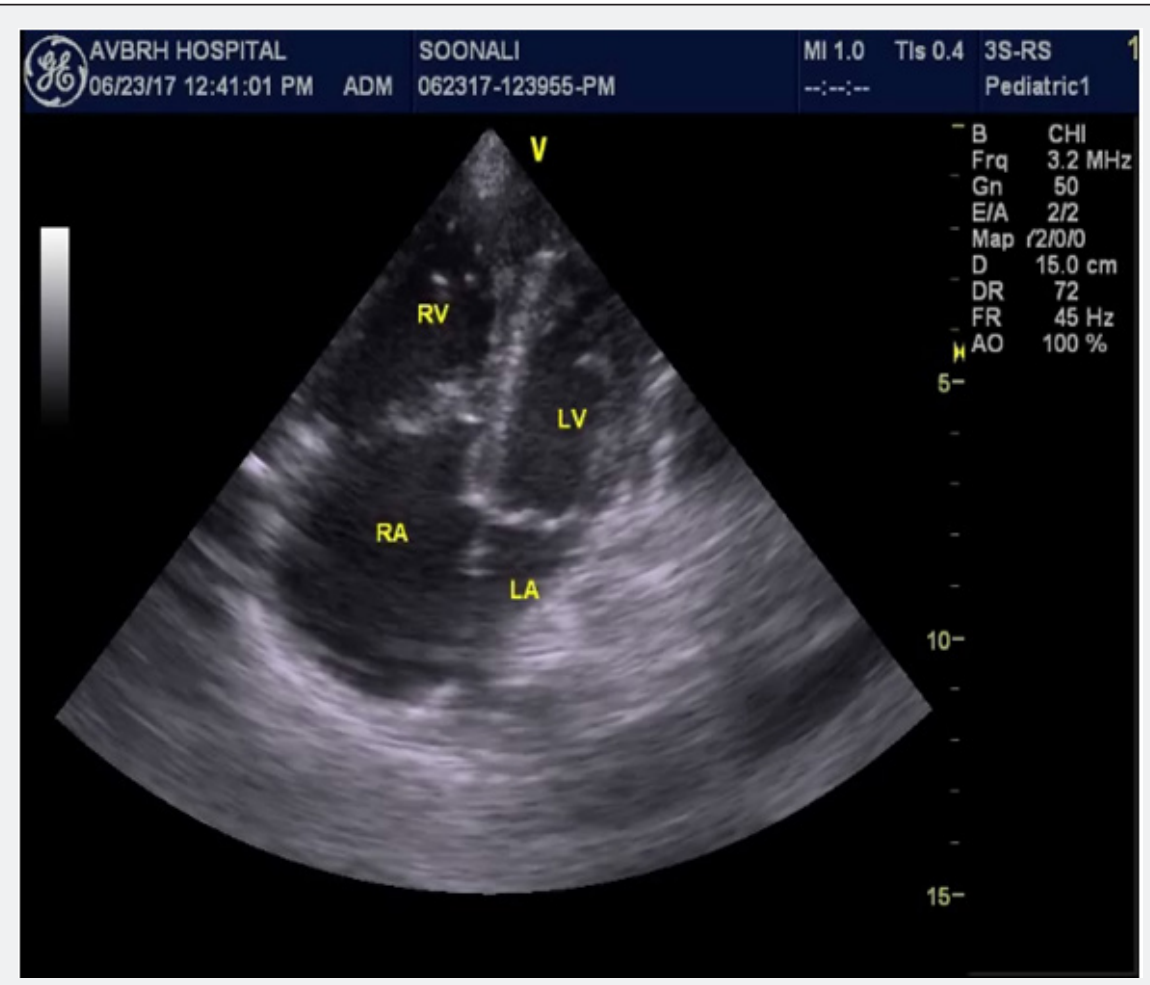

Figure 3: Echocardiographic image in the apical 4-chamber view shows apical displacement of the Tricuspid valve s/o Ebstein's anomaly.

\section{Discussion}

Brain abscess is a suppurative infection which is supratentorial in $85 \%$, infratentorial in $13 \%$ and combined in $2 \%$ cases. In our case, the child is 12 year old. The brain abscess is not common in this age, while the most common age group being 4-8 years and neonates. The stages of abscess formation are early cerebritis, late cerebritis, early capsulation and late capsulation. In the present case the child had a thick capsule which was removed 
during the surgery [3-5]. The clinical features are based on the specific cerebral region involved. If the frontal lobe is involved the abscess is initially silent, then drowsiness, personality changes, seizures, appearance of primitive reflexes and hemiparesis may appear. If the parietal lobe is invoved there are visual field defects. If the dominant hemisphere is involved dysphagia and if non dominant hemisphere is involved dyspraxia and spatial neglect are seen. If the temporal lobe is involved dysphasias are seen if dominant hemisphere is involved and quadranopsia is seen if non dominant hemisphere is involved. If the occipital lobe is involved it ruptures into ventricle causing ventriculitis/ependymitis, septic thrombophleibitis of the transverse sinus [6,7]. If the cerebellum is involved appendicular and gait ataxias, eye movement abnormalities are seen. If the brainstem is involved obstructive hydrocephalous, multiple cranial nerve palsies are seen. In our case the abscess was present in the temporoparietal region. But the child did not develop any dysphagia, dyspnea or visual field defects. The child had one episode of seizures which is common if frontal lobe is involved. Seizures can be the initial manifestation of brain abscess in upto $25-43 \%$ of cases [8]. Antiepileptics are required for children who develop seizures. Most authors recommend providing atleast 3 months of prophylaxis if no more seizures have occurred [9]. We have put the child on Levetiracetam to prevent the seizures.

In our case, EA was diagnosed which is a rare and complex congenital cardiac malformation. The pathological changes of EA are that septal, posterior and anterior leaflet of tricuspid valve are not adhere to tricuspid annulus which move down to RV spirally with textural anomalies and paramorphia of atrioventricular sulcus, valve, flap structure, and RV. However, clinical manifestations depend on the structural and functional alterations in the right cardiac chambers as well as in tricuspid valve morphology, and are more severe the greater the displacement of leaflet insertion. In the presence of septal defect, the increased right atrial pressure induced by the hemodynamic and functional changes resulting from EA cause reversed shunting (right-to-left), which is an anatomical substrate for paradoxical embolism that can lead to in stroke [10-12].

The causative organisms for brain abscess are aerobic and anaerobic streptococci with streptococcus milleri group, streptococcus pneumonia, group A, B streptococci, enterococus faecalis, Bacteroid species, Fusobacterium species, Prevotella species, Actinomyces species, Haemophilus aphrophilus, haemophilus parainfluenza, Haemophilus influenza, E.coli, Proteus species, mycobacterium species, listeria species Fungi like aspergillus and candida [2]. Anaerobicisolates include Bacteriod species and anaerobic streptococci [8]. The finding of sterile brain abscess was serious diagnostic dilemma until Ingham et al. [5] introduced the routine anaerobic culture technique with anaerobic organisms as causative factors [4].

In our case culture was sterile and the causative organism is not known. CT Brain finding of cerebritis in early stages are characterised by a parenchymal low density lesion [2]. In later stages the typical finding is a hypodense lesion with thin uniform ring enhancement on contrast CT imaging. MRI Brain with gadolinium on T1 weighted images brain abscess appears as a hypointense lesion with ring enhancement. On T2 weighted images it appears as a central hyperintense lesion encircled by a uniform hypointense capsule and surrounded by an irregular hyperintense area of perilesional edema $[3,13]$.

Treatment of choice is mainly third generation cephalosporins, vancomycin and Metronidazole. From the studies about $60 \%$ of children may have neurological and developmental sequelae. The commonest problems reported are hemiparesis, seizures, visual field defects, and learning difficulties [6-8]. Repeat MRI scan or CT scan of Brain after 2-4 weeks to document the resolution [3]. Surgery is needed if the abscess is $>2.5 \mathrm{~cm}$ in diameter, gas is present in the abscess, multiloculated, lesion located in the posterior fossa or fungus is identified. The duration of antibiotic therapy depends on the organism and response to treatment but usually for 4-6 weeks [2]. As the abscess was large surgical excision was done and the thick capsule was removed along with the drainage of the abscess. For EA, selection of surgical indications and timing of surgery depend on patients on set age, malformation type, development of valve and any other cardiac malformations. All these should be taken into overall consideration for EA surgery. Cone reconstruction of the tricuspid valve is an effective measure to treat EA. In conclusion, this is a very rare case report in a child with brain abscess caused by paradoxical embolization in Ebstein's anomaly.

\section{References}

1. Jost CHA, Connolly HM, Scott CG (2014) Increased risk of possible paradoxical embolic events in adults with ebstein anomaly and severe tricuspid regurgitation. Congenit Heart Dis 9(1): 30-37.

2. Charles G, Prober, Mathew R (2015) Brain abscess, (20 $0^{\text {th }}$ edn), Nelson text book of paediatrics, Vol. 2949-2950.

3. Jauhari P, Sahu JK (2015) Brain Abscess. In: Piyush Gupta (Ed.), PG text book of paediatrics, Vol. 2160-2172.

4. Rosenblum ML, Mampalan TJ, PonsVG (1986) Controversies in the management of brain abscess. Clinical Neurosurgery 33: 603-632.

5. Ingham HR, Selka JB, Roxby CM (1977) Bacteriological study of autogenic cerebral abscess: Chemotherapeutic role of metronidazole. Br Med J 2: 991.

6. Idriss ZA, Gutman LT, Knonfol NM (1978) Brain abscess in infants and children-current status of clinical findings, management andprognosis. Clinic Paediatr (Phila) 17(10): 738-746.

7. Hoffman HJ, Hendrick EB, Hiscox JL (1970) Cerebral abscesses in early infancy. J Neurosurgery 33(2): 172-177.

8. Carey ME, Chou SN, French LA (1971) Long term neurological residual in patients surviving brain abscess with surgery. J Neurosurg 34(5): 652-656.

9. Louvois D, Gortvai P, Hurley R (1977) Bacteriology of abscesses of CNS a multicentric prospective study. Br Med J (clin res) 2(6093): 981-984.

10. Lonnebakken MT, Greve G, Leirgul E (2008) Brain abscess caused by paradoxical embolization in Ebstein's anomaly. Eur J Echocardiogr 9(1): 105-106. 
11. Melao F, Correia AS, Maciel MJ (2013) Paradoxical embolism associated with Ebstein's anomaly in an adult: case report. Rev Port Cardiol 32(12): 1023-1025.

12. Liu J, Qiu L, Zhu Z (2011) Cone reconstruction of the tricuspid valve in Ebstein anomaly with or without one and a half ventricle repair. J Thorac Cardiovasc Surg 141(5): 1178-1183.
13. Llorens SX (2003) Brain abscess in children. Semin Paediatr Infect Dis 24(6): 108-114

Your next submission with Juniper Publishers will reach you the below assets

- Quality Editorial service

- Swift Peer Review

- Reprints availability

- E-prints Service

- Manuscript Podcast for convenient understanding

- Global attainment for your research

- Manuscript accessibility in different formats

( Pdf, E-pub, Full Text, Audio)

- Unceasing customer service

Track the below URL for one-step submission https://juniperpublishers.com/online-submission.php 